\title{
US National Academies report recommends changes to graduate STEM education
}

\author{
www.nap.edu
}

$\mathrm{T}^{\mathrm{s}}$ he frontiers of science, technology, engineering, and mathematics (STEM) have been advanced by generations of students who have earned graduate degrees and become experts and leaders across STEM. But a new report from the US National Academies of Sciences, Engineering, and Medicine (Academies) has recognized a significant evolution across the STEM enterprise, and has recommended a number of changes to better align US graduate education in STEM with the needs of the future.

The report, titled Graduate STEM Education for the 21st Century, acknowledges that the United States STEM education system has "served the nation extremely well" and points out substantial benefits to the economy, environment, national security, and public health. In addition, the report characterizes STEM education in the United States as the worldwide "gold standard," citing the large number of international students who choose to pursue STEM degrees in the United States as an important indicator. But despite the strength of these programs, the report mentions a number of recent surveys and studies that suggest graduates are not prepared to successfully apply their expertise across the broad spectrum of STEM-based careers.

Three of the members of the Academies committee responsible for the report_-Melanie Roberts, Kate Stoll, and Christine Ortiz-weigh in on the relevancy and challenges of tackling graduate STEM education reform. "Given that we have entered a new, technologydriven era since the last National Academies report on graduate education was released over two decades ago, it is important to revisit how the system is working," says Roberts, Director of State and Regional Affairs at Pacific Northwest National Laboratory. According to the report, the efficacy of graduate STEM programs has been impacted by a range of factors, including innovation- and technology-driven changes in workforce needs, significant shifts in the demographics of graduate student programs, and continuous growth in jobs that require proficiency in STEM. "The issues this report seeks to address have been brewing for years, but the confluence of changes in the scientific enterprise, technology, and demographics make this report urgent and timely," says Stoll, Massachusetts Institute of Technology (MIT) Washington Office Senior Policy Advisor. Roberts also points out the increasing number of calls for graduate STEM education reform over the last several years, a factor that she believes "demonstrates the need for serious study and conversation about whether and how to update the system."

While the graduate STEM education system is ripe for reform, the challenges are complex. Roberts and Stoll both point to the incentive system within academia-specifically the emphasis on publishing as the primary means to measure success - as a significant challenge. There is no doubt that the process of publication is an important part of a graduate STEM education, but the report recommends expanding the measures of success and rewarding effective teaching and mentorship practices. "We've been doing graduate education more or less the same way for decades, and it will take real changes to the incentive systems that are baked into the academic research enterprise to see significant changes in how we educate graduate STEM students," Stoll says. Roberts also points out that professors in academia are increasingly expected to take on a variety of roles, from research, mentoring, and teaching, to laboratory safety, to involvement in committees and recruiting, "with very little training, funding for non-research activities, or professional development support."

The report acknowledges the plethora of challenges involved in updating the graduate STEM education system but also emphasizes the need for a cultural shift toward a system that centers on students and prepares them for a broader range of STEM careers. The recommendations made within the report (see Table I) seek to modernize and refocus graduate STEM education. In addition, the report describes an "ideal" graduate education in STEM, identifies core competencies for master's and doctoral students across STEM disciplines, and encourages significantly expanded career exploration opportunities for graduate students. "Intentional design of programs around core competencies would help to shift the metrics of success for graduate education from primarily the number of academic publications to what students learn and how they are equipped to apply it in the future," Roberts says.

While modernizing the graduate STEM education system ultimately requires institutional changes, there are many ways that the government, private sector, and graduate students themselves can help drive the shift toward the report's recommended student-centric ideal. Federal agencies and other funders of graduate education could incentivize change through funding requirements or solicitations. According to Stoll, "the federal government could drive the changes articulated in the report by requiring that graduate students who are supported by research grants get access to professional development programs and quality mentoring." Roberts agrees and adds, "This must be coupled with resources that help students develop additional skills 
and knowledge necessary for successful STEM careers." Without the additional resources, Roberts believes the mandate could become "a compliance exercise" that would not ultimately achieve the goal of a better graduate STEM education.

The report is also unique in its call to graduate students themselves in changing the STEM education system. According to Stoll, "students can collectively be influential in making changes to graduate education," and the report lays out several recommendations to guide students in these efforts. Roberts adds that students should "be proactive designers of their own graduate education and careers," a viewpoint strongly supported within the report. In addition, the report emphasizes the importance of mentorship from across the spectrum of STEM careers, and Roberts points out that students should be resourceful in finding "multiple informal mentors, whether at their universities, in their professional societies, or beyond."

Advancing effective mentorship and teaching is one area where Ortiz, Morris Cohen Professor of Materials Science and Engineering at MIT, a former member of the Materials Research Society's Board of Directors, and Founder of Station 1 - a nonprofit organization that is building a foundation for the university of the future - believes that the materials community can lead in updating graduate STEM education. "The materials community has many characteristics that can facilitate advancement in these areas," says Ortiz, who specifically points to both the interdisciplinary nature of materials research and the diversity in career pathways. According to Ortiz, there are a number of other recommendations where materials scientists can lead the way, ranging from improving data collection, analytics, and transparency of educational outcomes, to helping achieve the report's "ideal" graduate education in STEM. Ortiz specifically emphasizes the potential for both leadership and positive impact on the materials community with the implementation of healthy learning and

\section{Table I. Recommendations}

Recommendation

Rewarding Effective Teaching and Mentoring

Institutional Support for Teaching and Mentoring

Comprehensive National and Institutional Data on Students and Graduates

Funding for Research on Graduate STEM Education

Ensuring Diverse, Equitable, and Inclusive Environments

A Dynamic Graduate STEM Education System

Stronger Support for Graduate Student Mental Health Services
Summary

Advancement procedures for faculty, including promotion and tenure policies and practices, should be restructured to strengthen recognition of contributions to graduate mentoring and education.

To improve the quality and effectiveness of faculty teaching and mentoring, institutions of higher education should provide training for new faculty and should offer regular refresher courses in teaching and mentoring for established faculty.

Graduate programs should collect, update, and make freely and easily accessible to current and prospective students information about master's- and PhD-level educational outcomes. In addition, to make appropriate future adjustments in the graduate education system, it is essential that comprehensive data sets about the system, its participants, and its outcomes be collected in a standard format, be fully transparent, and be easily accessible and transferable across multiple computer and statistical analysis platforms.

The National Science Foundation, other federal and state agencies, and private funders of graduate STEM education should issue calls for proposals to better understand the graduate education system and outcomes of various interventions and policies, including but not limited to the effect of different models of graduate education on knowledge, competencies, mindsets, and career outcomes.

The graduate STEM education enterprise should enable students of all backgrounds, including but not limited to racial and ethnic background, gender, stage of life, culture, socioeconomic status, disability, sexual orientation, gender identity, and nationality to succeed, by implementing practices that create an equitable and inclusive institutional environment.

The STEM education system should develop the capabilities to adjust dynamically to continuing changes in the nature of science and engineering activity and of STEM careers. This includes mechanisms to detect and anticipate such changes, experiment with innovative approaches, implement appropriate educational methods, and support institutional mechanisms on a larger scale.

Institutions should provide resources to help students manage the stresses and pressures of graduate education and maximize their success. Institutions of higher education should work with their faculty to recognize and ameliorate behaviors that exacerbate existing power differentials and create unnecessary stress for graduate students. research environments where diversity, equity, and inclusion are standard, as well as the integration of ethical and societal perspective into scientific and technological education. "These two recommendations seek to address core cultural, social, and interdisciplinary challenges facing all STEM fields and hold enormous potential for transformative advancements in the quality, creativity, productivity, and the equitable social impact of materials education and research," Ortiz says.

While it is undeniable that implementing the changes recommended within the report will require significant shifts across the STEM education enterprise, tackling this issue now will allow the United States to better prepare STEM students to meet the needs of the future. "Today, acceleration of science and technology is fundamentally driving the reorganization of humanity with equal potential for promise and peril," Ortiz says. "The mindset and education of future engineers and scientists is a critical factor in determining whether our shared future becomes more or less equitable, creative, meaningful, sustainable, and prosperous."

Jennifer A. Nekuda Malik 


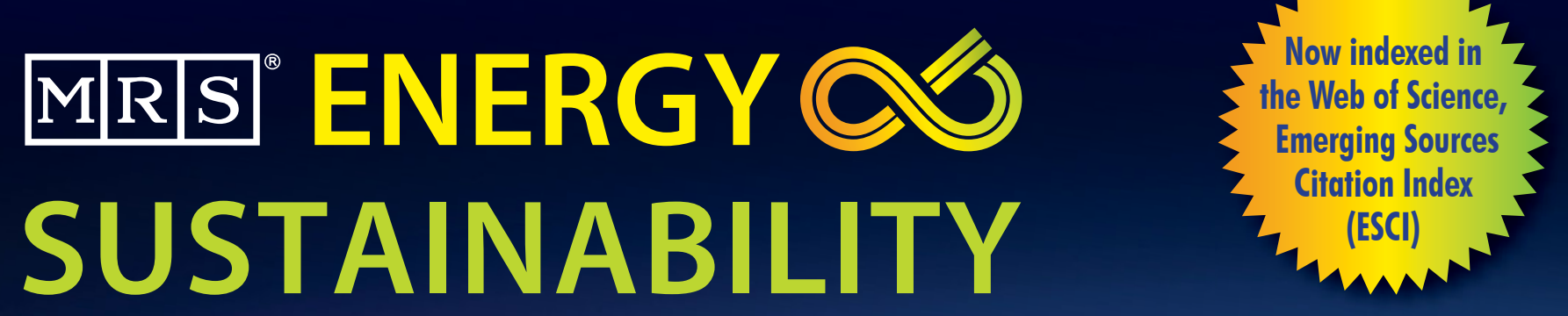

\section{science $\bigcirc$ technology $\propto$ socio-economics $\propto$ policy}
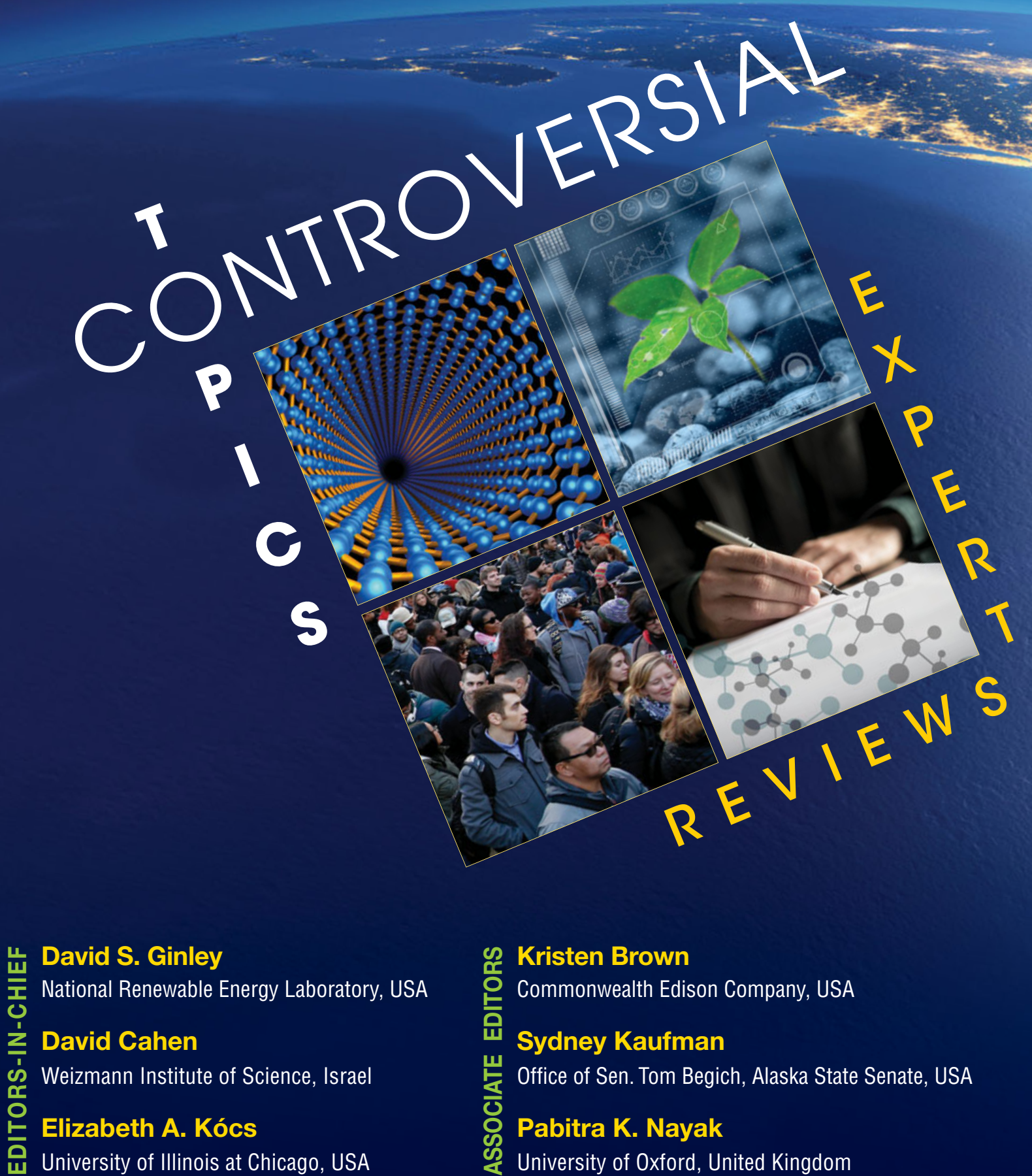